\title{
Chronic lymphocytic gastritis and protein losing gastropathy
}

\author{
J R CRAMPton, J O HUNTER, G NEALE, AND D G D Wight
}

Chronic lymphocytic gastritis (CLG) is a recently described histopathological entity characterised by the presence of lymphocytes in the surface and foveolar epithelium of the gastric mucosa. Previous accounts $^{1-3}$ have paid attention to both the endoscopic and histological features of the condition but the presenting features and clinical correlates of the pathology have not been clearly characterised. In this report we describe a new clinical association which is supported by a second case with similar features of protein loss. This is also the first report of CLG in which lymphocytic infiltration has also been shown in the duodenal mucosa.

\section{Case 1}

The patient, D M, a 34 year old solicitor, presented to his general practitioner with slow recovery from a flu like illness. Although his own symptoms were few his wife volunteered her concern over his lifestyle of frenctic activity, running and cycling over 10 miles per day, eating very little and having lost $7 \mathrm{~kg}$ in weight over the previous six months. On examination he was clearly wasted and thin, weight $50 \mathrm{~kg}$ with absent body fat, muscle wasting and mild ankle oedema. He was thought to be suffering from anorexia nervosa and was referred for a hospital opinion.

Initial investigations showed that he had a haemoglobin of $11.8 \mathrm{~g} / \mathrm{dl}(\mathrm{NR} 12.5-17.5 \mathrm{~g} / \mathrm{dl})$, mean cell volume $102 \mathrm{fl}(\mathrm{NR} 76-100 \mathrm{fl})$, leucocyte count $3 \cdot 0 \times$ $10^{4} / 1$ (NR $\left.4-11 \times 10^{4} / 1\right)$, lymphocyte count $1 \cdot 1 \times 10^{4} / 1$ (NR $\left.1.5-4 \times 10^{\circ} / 1\right)$ and platelet count $205 \times 10^{\circ} / 1(\mathrm{NR}$ $150-450 \times 10 \% / \mathrm{l})$. Erythrocyte sedimentation rate was $58 \mathrm{~mm} / \mathrm{h}$. There was no folate, $B_{12}$ or iron deficiency. Serum biochemical measurements revealed normal liver function tests (alkaline phosphatase $48 \mathrm{U} / \mathrm{l}$ (NR 30-135 U/I), ALT 48 (NR $7-40 \mathrm{U} / \mathrm{l})$, bilirubin $7 \mu \mathrm{mol} / 1$ (NR 2-17 $\mu \mathrm{mol} / \mathrm{l})$ ) but he was consistently hypoproteinaemic with a total protein concentration varying between $41-46 \mathrm{~g} / \mathrm{l}$ (NR 63-83 $\mathrm{g} / \mathrm{l})$ and albumin concentrations ranging from 18-24 g/l (NR 30-51 g/l). Immunoglobulin levels were low normal. Concentrations of calcium, magnesium and zinc were normal corrected for serum albumin. The urine contained no protein and renal function and plasma electrolytes were also normal.
By exclusion he was thought to be losing protein from the gut and this was confirmed by measurement of the excretion of ${ }^{51}-\mathrm{Cr}$ after an injection of ${ }^{51}-\mathrm{Cr}$ chloride. $(9 \cdot 87 \%$ of administered dose $(\mathrm{NR}<1 \cdot 5 \%))$. A barium meal and follow through examination showed coarse gastric folds and minimal dilatation of loops of small intestine. Upper gastrointestinal endoscopy revealed the stomach to have a prominent rugose lining but the duodenum appeared normal. Biopsies of the stomach were reported as showing chronic gastritis and duodenal biopsies as showing normal villous architecture with changes of nonspecific duodenitis only. A lymphangiogram showed no evidence of small intestinal lymphangiectasia. In

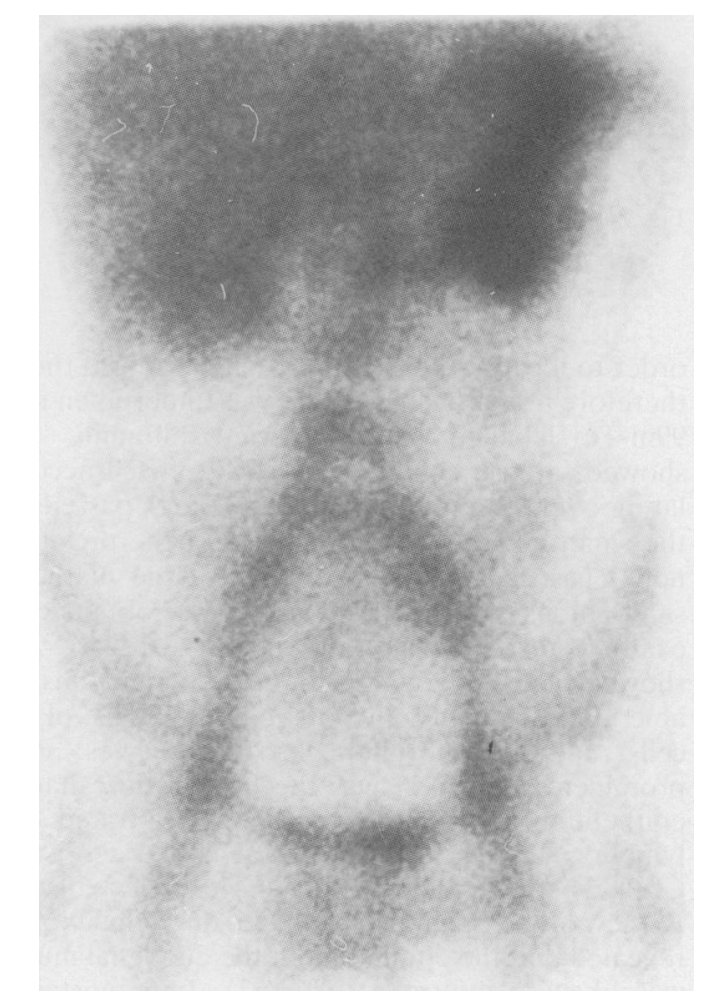

Fig. 1 Radionuclide study showing $99 m$-Tc human serum albumin collecting in the stomach and passing into the small intestine. 


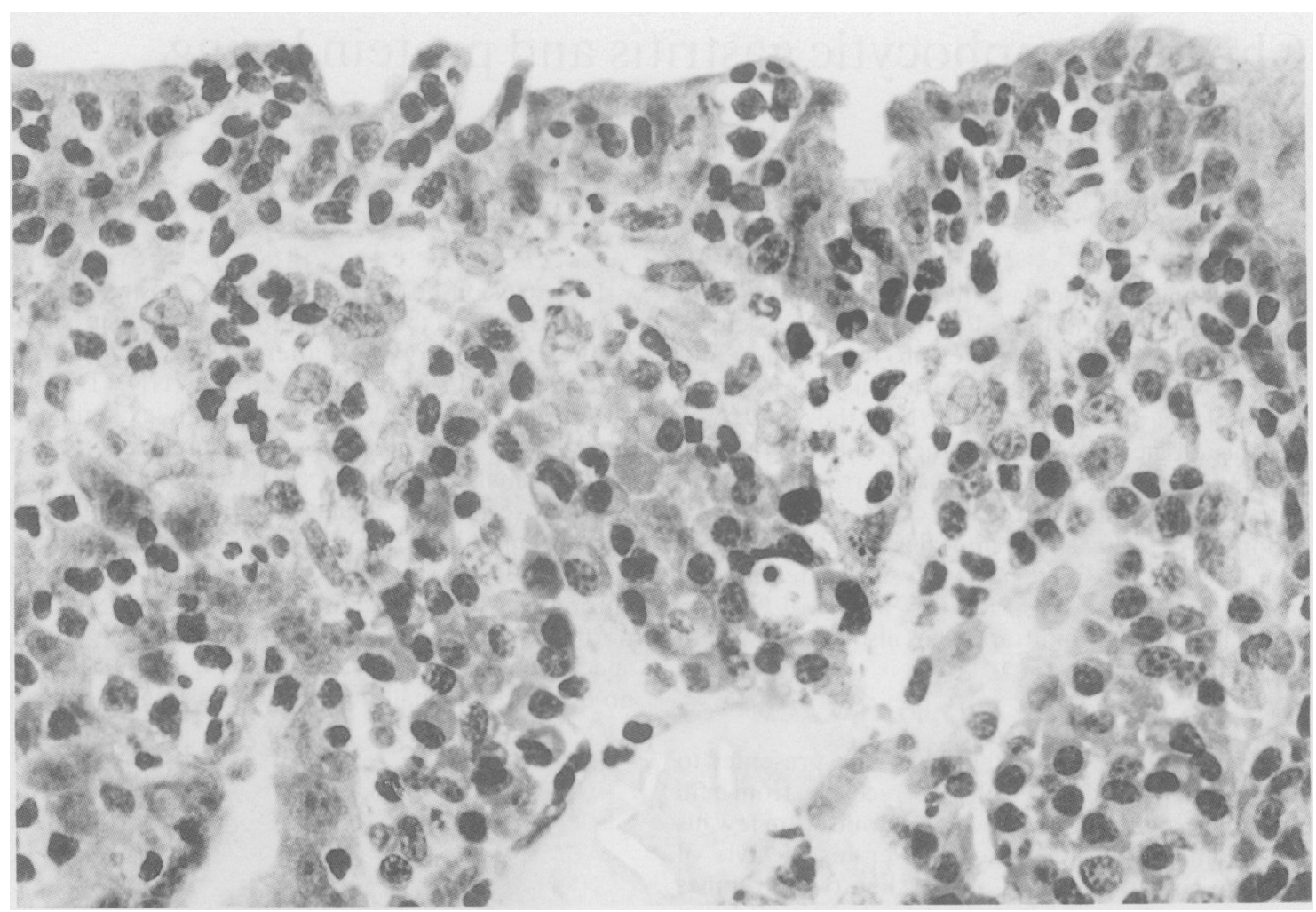

Fig. 2 Case 1: Stomach, showing intense lymphocytic infiltration of the surface and foveolar epithelium. $H \& E$.

order to localise the site of protein loss from the gut therefore a radionuclide study was undertaken using $99 \mathrm{~m}-\mathrm{Tc}$ labelled human serum albumin. This showed intense activity over the stomach accumulating over 30 minutes which only later passed into the small bowel (Fig. 1). In view of the previously noted gastric mucosal rugosity, a large diathermy snare biopsy of gastric mucosa was obtained, to examine for evidence of Menetrier's disease. This showed that the lamina propria contained considerable numbers of chronic inflammatory cells, plasma cells and polymorphonuclear leucocytes. Most prominent, however, was the observation that the epithelium itself was extensively infiltrated with lymphocytes (Fig. 2), an appearance characteristic of CLG. There was no evidence of Menetrier's disease. Review of the previously obtained duodenal biopsies revealed that the epithelium of the duodenal mucosa was likewise infiltrated. (Fig. 3). Immunostaining showed these lymphocytes to be of CD8, HML-1 pheno-type. (Fig. 4).

These studies therefore show that the patient had a protein losing gastropathy causing hypoproteinaemia in association with CLG. The patient himself continued to have little in the way of symptoms, but with continued hypoproteinaemia causing oedema casily controlled by diuretics.

Review of previous cases with unexplained gastrointestinal pathology revealed another patient who appears to fit into the same category.

\section{Case 2}

The patient $\mathrm{S} W$ a 50 year old woman, presented with a two month history of anorexia and weight loss. At presentation she appeared generally unwell and had moderate ankle oedema. Investigations showed a hacmoglobin of $10.6 \mathrm{~g} / \mathrm{dl}(\mathrm{NR} 11.5-16.5 \mathrm{~g} / \mathrm{dl})$, mean cell volume $85 \mathrm{fl}$ (NR 76-100 fl), leucocyte count $5 \cdot 2 \times 10^{\prime} / 1$ (NR $\left.4-11 \times 10^{\prime \prime} / 1\right)$ with lymphocytes $1.5 \times$ $10^{\%} / 1\left(\mathrm{NR} 1 \cdot 5-4 \times 10^{\%} / \mathrm{l}\right)$. The erythrocyte sedimentation rate was $2 \mathrm{~mm} / \mathrm{h}$. Liver function tests were normal although the serum albumin was low at $26 \mathrm{~g} / \mathrm{l}$ (NR 30-51 g/l) and the total protein also low at $44 \mathrm{~g} / \mathrm{l}$ (NR 63-83 g/l). Serum IgG and IgM were both low. 


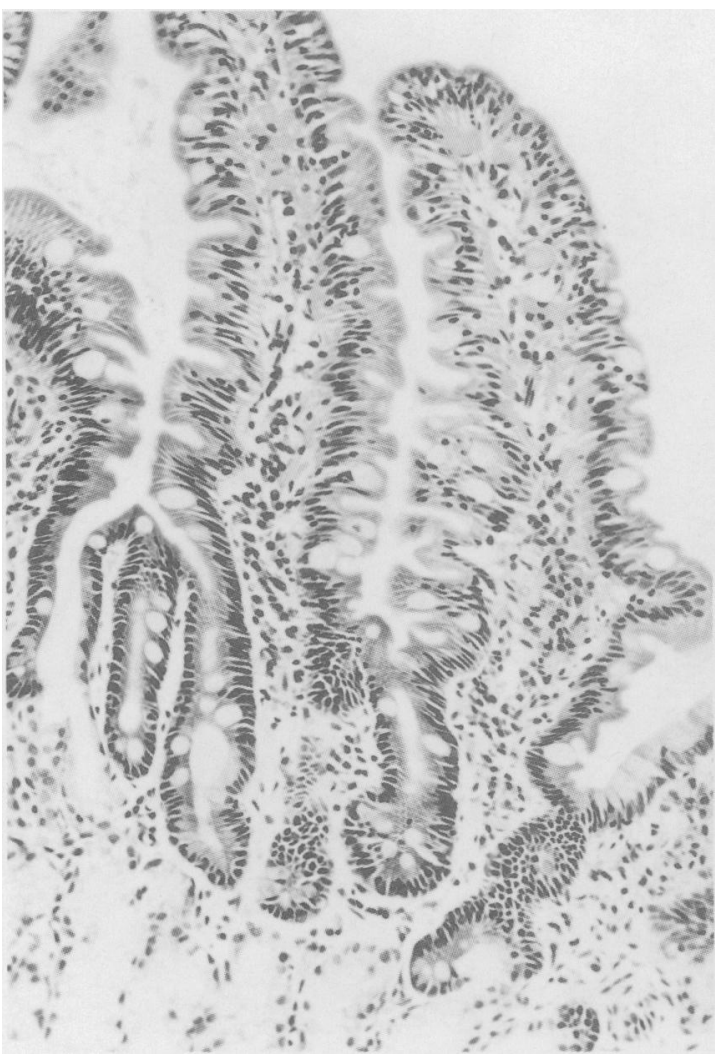

Fig. 3 Case I: Duodenum, showing normal overall villous morphology but a great increase in intraepithelial lymphocvtes. $H \& E$

Renal function was normal and there was no proteinuria. Faecal fat concentrations were not raised. Endoscopy showed thickened rugal folds with linear erythematous patches throughout the stomach topped by small yellow erosions. The duodenum appeared normal. Histology of the gastric biopsies showed typical CLG in addition to which there were Campylobacter-like organisms on the mucosal surface. The duodenal biopsies were normal. Quantification of the protein losses into the gut with ${ }^{5}-\mathrm{Cr}$ labelled albumin revealed a six day loss of $3.8 \%$ (NR $<1.5 \%$ ) confirming a protein losing state. In view of the observation of the Campylobacter organisms in this case the patient was treated with colloidal bismuth subcitrate and improved substantially over a period of three months during which time the albumin levels, total protein and immunoglobulin concentrations returned to normal. A repeat endoscopy showed striking improvement in the gastritis both macroscopically and histologically and Campylobacter like organisms were seen to be eradicated. Her oedema disappeared over this time and she became and has since remained asymptomatic.

\section{Discussion}

This is the first description of CLG with a protein losing gastropathy severe enough to produce hypoproteinaemia and gravitational oedema. The frequency with which this may occur is unknown but as hypoproteinaemia of this severity is unlikely to be missed it is probably rare. It is possible, however, that some patients with protein loss from the stomach have been misclassified as Menetrier's disease especially in view of the difficulty in diagnosing Menetrier's by mucosal biopsy. Chronic lymphocytic gastritis itself is an uncommon finding in gastric biopsy specimens: Haot et al found only 192 cases from 11,064 endoscopic biopsies'. These workers also showed the association of this histological appearance with the endoscopic observation of erosive, varioliform or aphthoid gastritis. Endoscopic features in our cases were also clearly abnormal with prominent broad rugal folds in the first and a florid varioliform gastritis in the second. The protein loss was clearly shown by the investigation and localised to the gastric mucosa. It appears that epithelial function was impaired by the presence of the lymphocytes and this is a situation which may be analogous to the intraepithelial lymphocytic infiltration of coeliac disease, a condition in which mild protein losing enteropathy often occurs. Although these patients did not have coeliac disease the duodenal mucosa was also the site of intracpithelial lymphocytes in case 1 which might be a whole gut response to a postulated luminal antigen. The nature of the antigen which may be involved is unknown. Some workers have suggested that the bacterium Campylobacter pylori may be the luminal stimulus to the development of CLG as this organism is commonly found in the antrum of these patients. ${ }^{3}$. On the other hand Campylobacter pylori infection is not a universal finding in patients with CLG and in most cases of Campylobacter gastritis the distinctive features of CLG are not found. In the two cases reported here Campylobacter-like organisms were identified histologically in one in which there appeared to be a therapeutic response treatment with bismuth. In order to further investigate the nature of the antigen responsible in other case dietary studies would be required which the other case dietary studies would be required which the patient was reluctant to undergo. An alternative strategy might be to suppress the immune response with steriods. We are currently considering the relative merits of these two approaches.

Addenbrooke's Hospital, Cambridge 


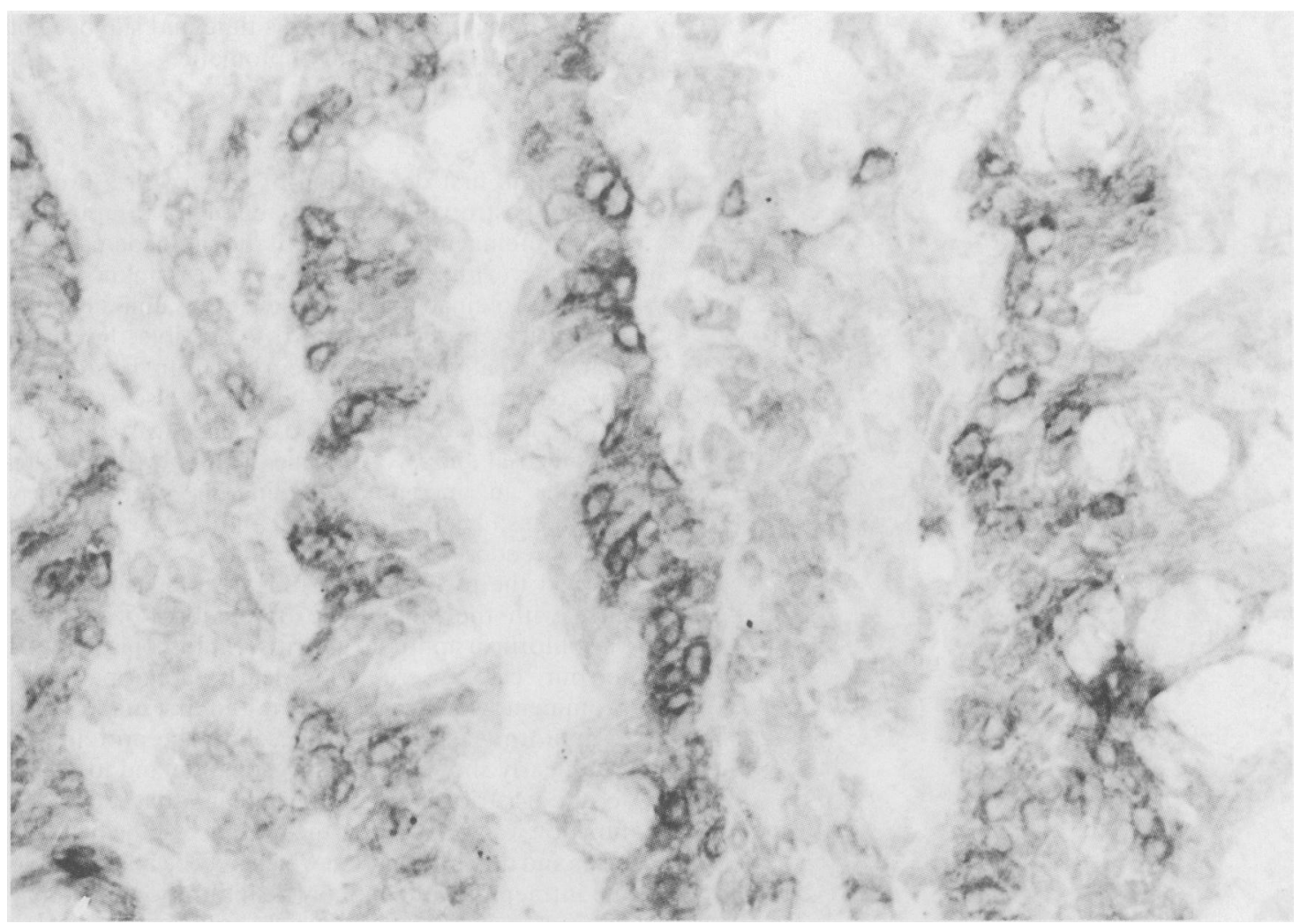

Fig. 4 Case 1: Duodenum, immunoperoxidase staining with an antibody to the CD8 epitope shows that all the intraepithelial cells have this phenotype.

\section{References}

1 Haot J, Hamichi L, Wallez L, Mainguet P. Lymphocytic gastritis: a newly described entity: a retrospective endoscopic and histological study. Gut 1988: 29: 1258-64.

2 Haot J, Delos M, Wallez L, Hardy N, Lenzen B, Jouret-
Mourin A. Les lymphocytes intracpitheliaux en pathologie gastrique inflammatoire. Acta Endoscopica 1988; 16: 61-9.

3 Dixon M, Wyatt J, Burke D. Rathbone B. Lymphocytic gastritis-relation to Campylobacter pylori infection. J Clin Pathol 1988; 154: 125-32. 